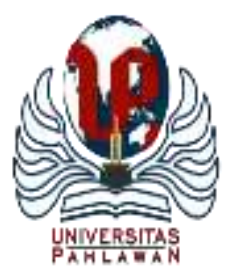

Edukatif : Jurnal Ilmu Pendidikan Volume 4 Nomor 1 Tahun 2022 Halm 316 - 322

EDUKATIF: JURNAL ILMU PENDIDIKAN

Research \& Learning in Education

https://edukatif.org/index.php/edukatif/index

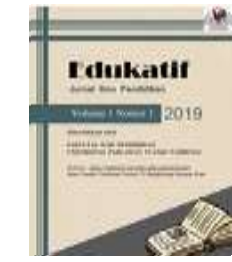

\title{
Upaya Meningkatkan Hasil Belajar Teknologi Jaringan Berbasis Luas (WAN) melalui Penerapan Model Pembelajaran Project Based Learning Mengunakan Aplikasi QR-Code
}

\author{
Mutia Liana $^{1 凶}$, Syukri Hamzah ${ }^{2}$ \\ SMKN 3 Lubuklinggau, Indonesia ${ }^{1}$, Universitas Bengkulu, Indonesia ${ }^{2}$ \\ E-mail : mutia.liana2020@ gmail.com ${ }^{1}$, syukrihamzah@ unib.ac.id $^{2}$
}

\begin{abstract}
Abstrak
Salah satu faktor yang mempengaruhi keberhasilan belajar adalah penerapan pendekatan pembelajaran. Dalam penelitian ini guru hendak menggunakan pendekatan pembelajaran model pembelajaran Project Based Learning menggunakan Aplikasi QR-Code. Jenis penelitian yang digunakan dalam penelitian ini adalah penelitian tindakan kelas. Pendekatan pembelajaran model pembelajaran Project Based Learning menggunakan Aplikasi QR-Code dapat meningkatkan hasil belajar siswa pada mata pelajaran Teknologi Jaringan Berbasis Luas (WAN) di Kelas XI-TKJ. Pada siklus I yang telah dilakukan didapat hasil bahwa dari 35 siswa kelas XI-TKJ terdapat 24 siswa atau 68,57\% telah mencapai nilai KKM 65 atau lulus, sedangkan 11 siswa atau 31,43\% tidak mencapai nilai KKM 65 atau tidak lulus. Pada perolehan hasil belajar siklus I menunjukan adanya peningkatan dibandingkan dengan hasil belajar pada tahap prasiklus. Siklus II yang telah dilakukan didapat hasil belajar bahwa dari 35 siswa kelas XI-TKJ terdapat 34 siswa atau 97,14\% telah mencapai nilai KKM 65 atau lulus.
\end{abstract}

Kata Kunci: Project Based Learning, QR-Code.

\begin{abstract}
One of the factors that influence the success of learning is the application of a learning approach. In this study, the teacher wanted to use a Project Based Learning learning approach using the QR-Code Application. The type of research used in this research was classroom action research. The learning approach of the Project Based Learning learning model Using the QR-Code Application could improve student learning outcomes in the subject of Broad-Based Network Technology (WAN) in Class XI-TKJ. In the first cycle that had been carried out, the results showed that from 35 students in class XI-TKJ were 24 students or $68.57 \%$ had reached the KKM 65 or passed, while 11 students or $31.43 \%$ did not reach the KKM 65 or did not pass. The acquisition of learning outcomes in the first cycle showed an increase compared to the learning outcomes at the pre-cycle stage. Cycle II that had been carried out, the results obtained are that from 35 students of class XI-TKJ were 34 students or $97.14 \%$ have achieved the KKM 65 or passed.
\end{abstract}

Keywords: Project Based Learning, QR-Code

Copyright (c) 2022 Mutia Liana, Syukri Hamzah

$\triangle$ Corresponding author

Email : mutia.liana2020@gmail.com

DOI $\quad:$ https://doi.org/10.31004/edukatif.v4i1.1817

ISSN 2656-8063 (Media Cetak)

ISSN 2656-8071 (Media Online) 
317 Upaya Meningkatkan Hasil Belajar Teknologi Jaringan Berbasis Luas (WAN) melalui Penerapan Model Pembelajaran Project Based Learning Mengunakan Aplikasi QR-Code - Mutia Liana, Syukri Hamzah

DOI: https://doi.org/10.31004/edukatif.v4i1.1817

\section{PENDAHULUAN}

Di era modern sekarang, kemajuan ilmu pengetahuan dan teknologi yang sangat pesat serta menyentuh pada semua aspek kehidupan manusia tak terkecuali di bidang pendidikan dan pengajaran. Pemerintah dewasa ini khususnya Departemen Pendidikan dan Kebudayaan berusaha untuk meningkatkan mutu pendidikan (Marryono Jamun, 2018; Lestari, 2018; Akmal \& Santaria, 2020).

Banyak permasalahan-permasalahan pembelajaran yang terjadi di sekolah. Seperti, rendahnya prestasi belajar siswa, malas belajar, dan tidak terlalu mementingkan sekolah, mereka lebih memilih bermain dari pada harus belajar. Permasalahan seperti itu rata-rata dimiliki oleh setiap lembaga pendidikan. Hal itu yang kemudian menjadi tanggung jawab pihak sekolah dan guru untuk berupaya dalam memperbaiki keadaan tersebut, agar siswa mampu menjadi manusia yang berpengetahuan dan bermoral tinggi yang berlandaskan agama (Nugroho, 2015; A. S. Lestari, 2014).

Adapun permasalahan-permasalahan tersebut muncul dari keseharian siswa di kelas XI-TKJ.1 SMK Negeri 3 Lubuklinggau tahun pelajaran 2021/2022 tempat penelitian ini banyak sekali ditemukan permasalahan. Seperti dalam pembelajaran Teknologi Jaringan Berbasis Luas (WAN) pada materi Jaringan Fiber Optic. Pada saat pembelajaran, siswa kurang antusias dan kurang peduli terhadap apa yang disampaikan guru, mereka lebih mementingkan hal lain dari pada belajar, seperti menggambar, bicara sendiri dengan teman di dekatnya. Hal itu tentu sangat mengganggu dan tidak memungkinkan untuk memperoleh hasil pembelajaran yang maksimal. Dalam kondisi yang demikian, tentu akan sangat berpengaruh terhadap prestasi atau hasil belajar siswa. Jika kondisi seperti ini tidak secepatnya ditanggulangi, maka sangat mungkin kualitas lembaga akan menjadi menurun, karena salah satu indikator keberhasilan lembaga adalah mampu mencetak lulusan yang baik, sesuai dengan yang diharapkan oleh lembaga tersebut (Prihatini, 2018; Naibaho et al., 2021).

Berdasarkan identifikasi masalah di atas, perlu dilakukan perbaikan proses pembelajaran agar siswa dapat berinteraksi lebih aktif, dan semangat dalam mengikuti pembelajaran Teknologi Jaringan Berbasis Luas (WAN) khususnya pada materi Jaringan Fiber Optic sehingga dapat meningkatkan aktivitas dan hasil belajar siswa kelas XI-TKJ.1 SMK Negeri 3 Lubuklinggau. Sebagai konsekuensi logis dari ketidaktepatan penggunaan metode/model pembelajaran sering menimbulkan kebosanan, kurang dipahami, bergaya menolong, dan monoton yang akhirnya menimbulkan siswa menjadi apatis. Oleh karena itu untuk menghindari hal tersebut guru hendaknya cermat dalam memilih dan menggunakan strategi pembelajaran baik pendekatan, metode/model pembelajaran terutama yang banyak melibatkan siswa. Sebagaimana diketahui banyak sekali macam strategi pembelajaran yang telah dirumuskan sebagai alternatif guru dalam menyampaikan materi pelajaran, salah satunya ialah dengan menggunakan model pembelajaran berbasis projek (Rezeki et al., 2015; Efrimal et al., 2017; Nisa, 2021).

Berkenaan dengan penerapan pembelajaran berbasis proyek untuk meningkatkan aktivitas belajar dan hasil belajar, kelebihan pembelajaran tersebut menurut (Panjaitan \& Simangunsong, Ika Trisni Sihombing, 2020; Anggraini \& Wulandari, 2021) diantaranya, "Meningkatkan motivasi, meningkatkan pemecahan masalah, meningkatkan kolaborasi, meningkatkan keterampilan mengelola sumber." Peserta didik akan lebih termotivasi karena ternyata bekerja keras meyelesaikan proyek merupakan kegiatan yang menyenangkan. Berbagai sumber yang mendiskripkan media belajar berbasis proyek akan membuta peserta didik lebih aktif dan berhasil memecahkan problem yang kompleks. Dalam penyelesaian proyek sangat dibutuhkan pengembangan keterampilan komunikasi dalam kerja kelompok. Apabila diimplementasikan secara baik, maka peserta didik akan belajar dan praktik dalam mengorgaganisasikan proyek, membuat alokasi waktu dan sumber- sumber lain seperti perlengkapan untuk menyelesaikan proyek.

Berdasarkan paparan masalah tersebut, peneliti tertarik untuk menerapkan model pembelajaran berbasis proyek sebagai solusi untuk mengupayakan perbaikan dalam proses pembelajaran Teknologi Jaringan 
318 Upaya Meningkatkan Hasil Belajar Teknologi Jaringan Berbasis Luas (WAN) melalui Penerapan Model Pembelajaran Project Based Learning Mengunakan Aplikasi QR-Code - Mutia Liana, Syukri Hamzah

DOI: https://doi.org/10.31004/edukatif.v4i1.1817

Berbasis Luas (WAN) materi Jaringan Fiber Optic pada siswa kelas XI- TKJ.1 SMK Negeri 3 Lubuklinggau, yang diharapkan dapat mewujudkan kompetensi para peserta didik menjadi lebih meningkat. Adapun judul penelitian ini adalah "Upaya Meningkatkan Hasil Belajar Teknologi Jaringan Berbasis Luas (WAN) Pada Materi Jaringan Fiber Optic Melalui Penerapan Model Pembelajaran Project Based Learning Mengunakan Aplikasi QR-Code Kelas XI-TKJ.1 SMK Negeri 3 Lubuklinggau Tahun Pelajaran 2021/2022”.

\section{METODE PENELITIAN}

Penelitian ini merupakan penelitian tindakan kelas (Classroom Action Research). Penelitian tindakan kelas adalah salah satu strategi pemecahan masalah yang memanfaatkan tindakan nyata dan proses pengembangan kemampuan dalam mendeteksi dan memecahkan masalah (Khasinah, 2013; Lamajau, 2014). Penelitian ini menggunakan pendekatan kualitatif deskriptif. Desain Penelitian Tindakan Kelas di atas adalah:

1. Perencanaan awal, sebelum mengadakan penelitian, peneliti menyusun rumusan masalah, tujuan dan membuat rencana tindakan, termasuk didalamnya instrumen penelitian dan perangkat pembelajaran.

2. Tindakan yaitu meliputi tindakan yang dilakukan oleh peneliti dengan peran sebagai upaya mengetahui proses pelaksanaan tindakan Pendekatan pembelajaran yang diterapkan dalam hal ini adalah langkah kegiatan pembelajaran dengan Model Pembelajaran Project Based Learning pada mata pelajaran Teknologi Jaringan Berbasis Luas (WAN) dalam meningkatkan aktivitas dan hasil belajar Teknologi Jaringan Berbasis Luas (WAN) pada materi Jaringan Fiber Optic. Dari hasil observasi ini didapatkan hasil dari fokus masalah yang ingin dipecahkan yaitu Aktivitas dan Hasil Belajar pada pelajaran Teknologi Jaringan Berbasis Luas (WAN) materi Jaringan Fiber Optic siswa kelas XI-TKJ.1 SMK Negeri 3 Lubuklinggau tahun pelajaran 2021/2022.

3. Observasi, dalam tahap observasi ini, peneliti melakukan kegiatan observasi terhadap tindakan yang sedang berlangsung selama proses pembelajaran. Observasi ini bisa dilakukan oleh peneliti sendiri atau dengan bantuan pihak lain sebagai observer. Kegiatan observasi ini dilakukan untuk mengetahui kesesuaian perencanaan disusun sebelumnya dengan pelaksanaan yang dilakukan selama proses pembelajaran berlangsung. Kegiatan observasi dalam penelitian ini dilakukan untuk mengetahui bentuk penerapan Model Pembelajaran Project Based Learning serta kemampuan berpikir konstruktif siswa pada proses pembelajaran Teknologi Jaringan Berbasis Luas (WAN).

4. Refleksi, peneliti mengkaji, melihat dan mempertimbangkan hasil atau dampak dari tindakan yang dilakukan berdasarkan lembar pengamatan atau lembar observasi yang diisi oleh pengamat.

5. Perbaikan rencana, berdasarkan hasil refleksi dari pengamat membuat rancangan yang direvisi untuk dilaksanakan pada siklus berikutnya.

Dalam penelitian ini menggunakan pendekatan kualitatif yang menjadi alat utama adalah manusia, artinya melibatkan peneliti sendiri sebagai instrumen dengan memperhatikan kemampuan peneliti dalam hal bertanya, melacak, mengamati, memahami dan mengabstraksikan sebagai alat penting yang tidak dapat diganti dengan cara lain. Penelitian dilaksanakan di kelas XI-TKJ.1 SMK Negeri 3 Lubuklinggau yang beralamat di Jalan Pioner Nomor 46 B Kelurahan Air Kuti Kecamatan Lubuklinggau Timur I Kabupaten Lubuklinggau Provinsi Sumatera Selatan. Penelitian dilaksanakan mulai bulan Agustus sampai Oktober 2021. Subyek penelitian ini adalah siswa kelas XI-TKJ.1 SMK Negeri 3 Lubuklinggau semester ganjil tahun ajaran 2021/2022 yang berjumlah 35 orang siswa. 
319 Upaya Meningkatkan Hasil Belajar Teknologi Jaringan Berbasis Luas (WAN) melalui Penerapan Model Pembelajaran Project Based Learning Mengunakan Aplikasi QR-Code - Mutia Liana, Syukri Hamzah

DOI: https://doi.org/10.31004/edukatif.v4i1.1817

\section{HASIL DAN PEMBAHASAN PENELITIAN}

Berdasarkan hasil tindakan pada siklus I siswa kelas XI-TKJ.1 SMK Negeri 3 Lubuklinggau menunjukan bahwa hasil belajar Teknologi Jaringan Berbasis Luas (WAN) materi Jaringan Fiber Optic mengalami peningkatan dibandingkan pada tahap prasiklus. Adapun hasil belajar siswa kelas XI-TKJ.1 SMK Negeri 3 Lubuklinggau siklus 1 adalah sebagai berikut:

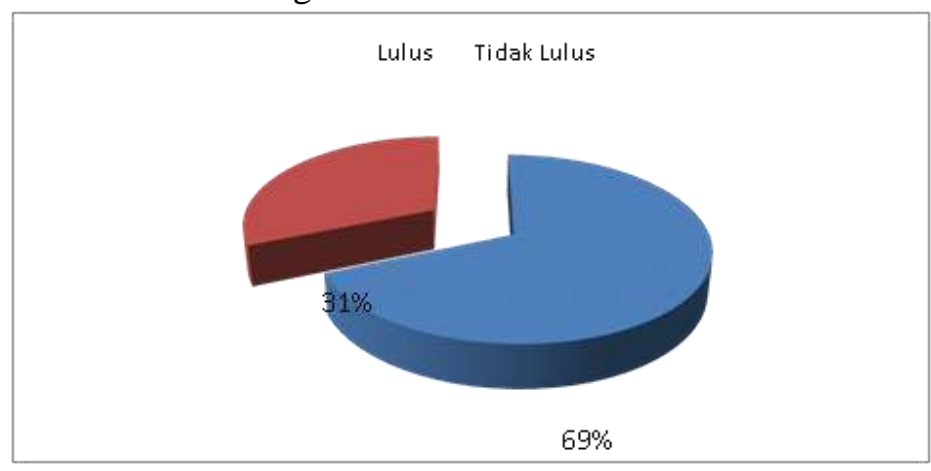

Gambar 1. Hasil Belajar Siklus I

Berdasarkan diagram diatas juga dapat dilihat adanya peningkatan dari prasiklus. Siswa yang mendapat nilai lebih dari atau sama dengan 65 adalah 24 siswa dengan persentas $68,57 \%$ berhasil mencapai nilai KKM 65. Namun hal ini juga masih dalam kategori rendah yang disesuaikan dengan tabel kriteria hasil belajar.

Siswa masih belum terbiasa belajar kelompok dalam pembelajaran kooperatif, sehingga diskusi kelompok tidak terlaksana secara optimal karena banyak siswa yang masih sibuk bermain atau mengobrol sendiri. Selain itu masih banyak yang menyerahkan semua tugas kepada siswa yang dianggap lebih pandai, sehingga tidak terjadi diskusi. Berdasarkan hasil observasi diatas, maka perlu suatu tindakan penyelesaian untuk memperbaiki penerapan pembelajaran menggunakan model pembelajaran Project Based Learning antara lain: 1) Guru harus bisa memberikan penjelasan kembali tentang tahapan Metode tugas kelompok, dan memotivasi siswa untuk berani mengeluarkan ide-ide yang ada pada pikirannya pada saat diskusi kelompok maupun pada diskusi kelas. 2) Guru harus bisa mengatur waktu agar sesuai dengan apa yang direncanakan. 3) Hasil belajar secara klasikal belum tercapai karena hanya mencapai 24 siswa tuntas yaitu $68,57 \%$ dan 11 siswa tidak tuntas yaitu 31,43\%. Hasil refleksi mengindikasikan bahwa pentingnya dilaksanakan siklus II karena masih banyak yang perlu diperbaiki dalam pelaksanaan pembelajaran menggunakan model pembelajaran Project Based Learning sehingga dapat meningkatkan aktivitas siswa dan hasil belajar siswa Pada pembelajaran Teknologi Jaringan Berbasis Luas (WAN) materi Jaringan Fiber Optic.

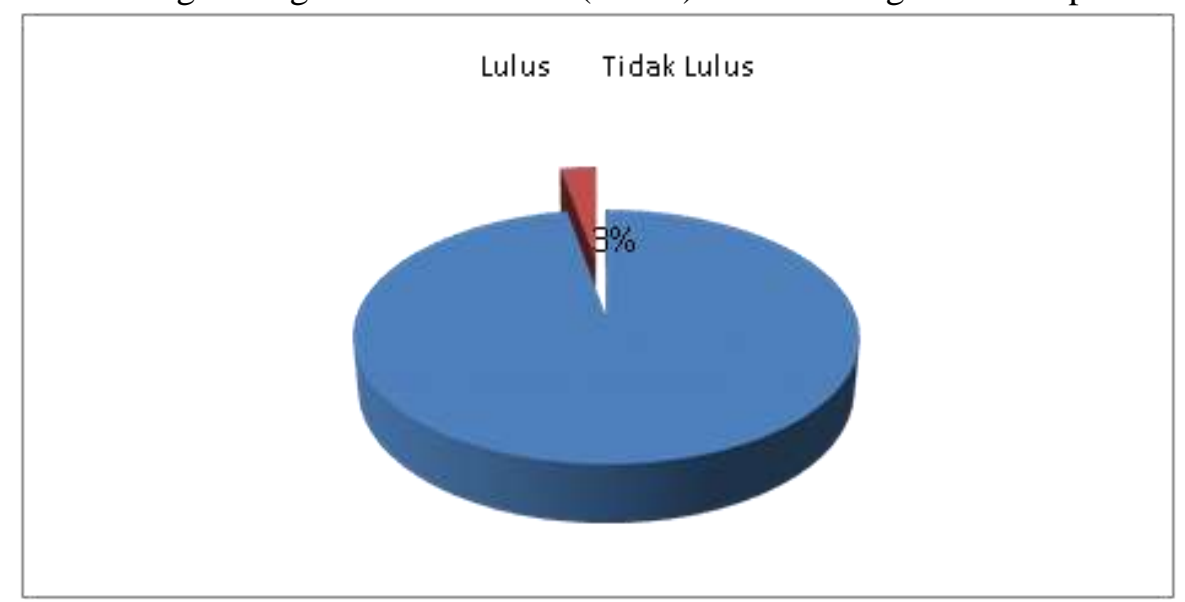

Gambar 2. Hasil Belajar Siklus 2 
320 Upaya Meningkatkan Hasil Belajar Teknologi Jaringan Berbasis Luas (WAN) melalui Penerapan Model Pembelajaran Project Based Learning Mengunakan Aplikasi QR-Code - Mutia Liana, Syukri Hamzah

DOI: https://doi.org/10.31004/edukatif.v4i1.1817

Peningkatan yang signifikan dari tahap siklus I. Pada tahap siklus II siswa yang mendapat nilai lebih dari atau sama dengan 65 adalah sebanyak 34 siswa dengan persentas 97,14\% berhasil mencapai nilai KKM 65. Hal tersebut menunjukan bahwa pelaksanaan pembelajaran pada siklus II masuk dalam kategori tinggi dan memenuhi syarat ketuntasan target yaitu $75 \%$ dari jumlah siswa secara keseluruhan atau sudah memenuhi kriteria ketuntasan secara klasikal, dan berarti tidak perlu diadakan lagi siklus III.

Dalam penelitian yang dilakukan oleh peneliti dibagi menjadi dua siklus dalam kegiatan proses belajar. Dengan data yang dikumpul mencakup aktivitas guru, aktivitas siswa, dan hasil belajar. Dari data hasil mewawancarai peserta didik. Dengan siklus I dan II, dari hasil penelitian dengan menggunakan model pembelajaran Project Based Learning (PBL) pada pembelajaran Teknologi Jaringan Berbasis Luas (WAN) materi Jaringan Fiber Optic. Model pembelajaran Project Based Learning, model pembelajaran ini melibatkan siswa secara langsung dalam proses pembelajaran melalui kegiatan penelitian untuk mengerjakan dan menyelesaikan suatu proyek tertentu. Walaupun model pembelajaran Project Based Learning dapat dikatakan sebagai model lama, tetapi model ini memiliki banyak keunggulan dibandingkan model pembelajaran lain sehingga model PBL banyak digunakan dan terus dikembangkan. Salah satu keunggulan tersebut adalah bahwa model PBL dinilai merupakan salah satu model pembelajran yang sangat baik dalam mengembangkan berbagai keterampilan dasar yang harus dimiliki siswa termasuk keteramplan berpikir, keterampilan membuat keputusan, kemampuan berkreativitas, kemampuan memecahkan masalah, dan sekaligus dipandang efektif untuk mengembangkan rasa percaya diri dan manajemen diri para siswa (Suciani et al., 2018; Nurfitriyanti, 2016)

Hal yang sama diungkapkan (Santoso et al., 2015; Yulianto, Aris, Fatchan .A, Astina, 2017) menyatakan bahwa pembelajaran Project Based Learning merupakan model pembelajaran yang menggunakan masalah sebagai langkah awal dalam mengumpulkan dan mengintegrasikan pengetahuan baru berdasarkan pengalamannya dalam beraktivitas secara nyata. Pembelajaran Project Based Learning dirancang untuk digunakan pada permasalahan kompleks yang diperlukan siswa dalam melakukan investigasi dan memahaminya. Pembelajaran Project Based Learning adalah sebuah model pengelolaan pembelajaran seputar proyek (Sunarsih, 2016; Granado-Alcón et al., 2020).

\section{KESIMPULAN}

Berdasarkan hasil penelitian menunjukan bahwa penerapan Model Pembelajaran Project Based Learning Mengunakan Aplikasi QR-Code dapat meningkatkan aktivitas dan hasil belajar Teknologi Jaringan Berbasis Luas (WAN) materi Jaringan Fiber Optic siswa kelas XI-TKJ.1 SMK Negeri 3 Lubuklinggau Tahun Pelajaran 2021/2022. Hal tersebut ditunjukan dengan peningkatan aktivitas pada siklus I memperoleh score 12 yang masuk dalam kategori Baik dan pada siklus II meningkat dengan perolehan skor sebesar 15 yang masuk dalam kategori Sangat Baik. selain aktivitas, hasil belajar siswa juga meningkat pada tahap pra siklus, Siklus I, dan Siklus II. Pada tahap prasiklus yaitu dari 35 siswa diperoleh data bahwa terdapat 23 atau $65,71 \%$ siswa yang memperoleh nilai kurang dari KKM 65 dan 12 atau 34,29\% siswa yang nilainya lebih dari KKM 65 dengan nilai rata-rata sebesar 63.57, Selanjutnya siklus I dari 35 siswa diperoleh data bahwa terdapat 11 siswa atau $31,43 \%$ siswa yang memperoleh nilai kurang dari KKM 65 dan 24 siswa atau 68,57\% siswa yang nilainya lebih dari KKM 65 dengan nilai rata-rata sebesar 67.71, dan pada siklus II dari 35 siswa diperoleh data bahwa terdapat 1 siswa atau 2,86\% yang memperoleh nilai kurang dari KKM 65 dan ada 34 siswa atau 97,14\% yang nilainya lebih dari KKM 65 dengan nilai rata-rata sebesar 73.8 
321 Upaya Meningkatkan Hasil Belajar Teknologi Jaringan Berbasis Luas (WAN) melalui Penerapan Model Pembelajaran Project Based Learning Mengunakan Aplikasi QR-Code - Mutia Liana, Syukri Hamzah

DOI: https://doi.org/10.31004/edukatif.v4i1.1817

\section{DAFTAR PUSTAKA}

Akmal, M. J., \& Santaria, R. (2020). Mutu Pendidikan Era Revolusi 4.0 Di Tengah Covid-19. Journal Of Teaching Dan Learning Research, 2(2), 1-12. Http://Ejournal.Iainpalopo.Ac.Id/Index.Php/Jtlr/Article/View/1415

Anggraini, P. D., \& Wulandari, S. S. (2021). Analisis Penggunaan Model Pembelajaran Project Based Learning Dalam Peningkatan Keaktifan Siswa. Jurnal Pendidikan Administrasi Perkantoran, 9(2), 296.

Efrimal, F., Kurnia, N., \& Wasidi. (2017). Penerapan Model Project Based Learning (Pjbl) Untuk Meningkatkan Kecermatan Dan Kreasi Seni Rupa (Studi Pada Siswa Kelas Xi Sma Negeri 3 Seluma). Diadik: Jurnal Ilmiah Teknologi Pendidikan, 7(2), 48-61. Https://Www.Google.Com/Url?Sa=T\&Source=Web\&Rct=J\&Url=Http://Jurnal.Fkip.Uns.Ac.Id/Index.P hp/Pgsdkebumen/Article/Download/11961/8533\&Ved=2ahukewjc5ocphoviahudeiskhsuncrkqfjabegqibx ab\&Usg=Aovvaw0gq5yqzrbheuxh758-Y9yt

Granado-Alcón, M. D. C., Gómez-Baya, D., Herrera-Gutiérrez, E., Vélez-Toral, M., Alonso-Martín, P., \& Martínez-Frutos, M. T. (2020). Project-Based Learning And The Acquisition Of Competencies And Knowledge Transfer In Higher Education. Sustainability (Switzerland), 12(23), 1-18. Https://Doi.Org/10.3390/Su122310062

Khasinah, S. (2013). Classroom Action Research. Jurnal Pionir, Volume 1, Nomor 1, 1(2), 33-61.

Lamajau, E. (2014). Peningkatan Kemampuan Keterampilan Berbicara Siswa Kelas V Sdn Sampaka Kec. Bualemo Kab. Banggai Melalui Metode Diskusi Kelompok. Jurnal Kreatif Tadulako Online, 5(1), 201211. Http://Jurnal.Untad.Ac.Id/Jurnal/Index.Php/Jkto/Article/View/3770

Lestari, A. S. (2014). Pemanfaatanteknologi Informasi Dalam Pendidikan Karakter. November, 1-20.

Lestari, S. (2018). Peran Teknologi Dalam Pendidikan Di Era Globalisasi. Edureligia; Jurnal Pendidikan Agama Islam, 2(2), 94-100. Https://Doi.Org/10.33650/Edureligia.V2i2.459

Marryono Jamun, Y. (2018). Dampak Teknologi Terhadap Pendidikan. 10, 48-52.

Naibaho, S. W., Elindra, R., Siregar, E. Y., Mipa, F., Pendidikan, I., \& Selatan, T. (2021). Analisis FaktorFaktor Penyebab Rendahnya Motivasi Belajar Siswa Mts Negeri 1 Tapanuli Tengah Disaaat Pandemi Covid-19 Oleh. Mathematic Education Journal)Mathedu, 4(2), 304. Http://Journal.Ipts.Ac.Id/Index.Php/

Nisa, A. R. K. (2021). Efektivitas Model Pembelajaran Berbasis Proyek Dalam Pjj Terhadap Pemhaman Materi. Alinea: Jurnal Bahasa, Sastra, Dan Pengajaran, $10(1), 61$. Https://Doi.Org/10.35194/Alinea.V10i1.1186

Nugroho, M. A. (2015). Pemanfaatan Teknologi Informasi Dalam Peningkatan Mutu Pendidikan Islam Di Madrasah. Mudarrisa: Journal Of Islamic Education, 6(1), 30. Https://Doi.Org/10.18326/Mdr.V6i1.758

Nurfitriyanti, M. (2016). Model Pembelajaran Project Based Learning Terhadap Kemampuan Pemecahan Masalah Matematika. Formatif: Jurnal Ilmiah Pendidikan Mipa, 6(2), 149-160. Https://Doi.Org/10.30998/Formatif.V6i2.950

Panjaitan, J., \& Simangunsong, Ika Trisni Sihombing, H. B. M. (2020). Penerapan Project Based Learning (Pjbl) Berbasis Hots Untuk Menciptakan Media Pembelajaran Yang Inovatif. Jurnal Pendidikan Fisika, $9(2)$.

Prihatini, N. (2018). Analisis Berbagai Faktor Penyebab Rendahnya Motivasi Belajar Siswa Kelas Iv Sdn 3 Tebaban. Jurnal Didika: Wahana Ilmiah Pendidikan Dasar, 4(1), 56. Https://Doi.Org/10.29408/Didika.V4i1.1198

Rezeki, R., Nurhayati, N., \& Mulyani, S. (2015). Penerapan Metode Pembelajaran Project Based Learning (Pjbl) Disertai Dengan Peta Konsep Untuk Meningkatkan Prestasi Dan Aktivitas Belajar Siswa Pada Materi Redoks Kelas X-3 Sma Negeri Kebakkramat Tahun Pelajaran 2013 / 2014. Jurnal Pendidikan 
322 Upaya Meningkatkan Hasil Belajar Teknologi Jaringan Berbasis Luas (WAN) melalui Penerapan Model Pembelajaran Project Based Learning Mengunakan Aplikasi QR-Code - Mutia Liana, Syukri Hamzah

DOI: https://doi.org/10.31004/edukatif.v4i1.1817

Kimia Universitas Sebelas Maret, 4(1), 74-81.

Santoso, P., Magister, P., Ekonomi, P., Maret, U. S., Learning, P. B., \& Learning, P. B. (2015). Penggunaan Model Pembelajaran Project Based Learning ( Pbl ) Sebagai Upaya Peningkatan Hasil Belajar.

Suciani, T., Lasmanawati, E., \& Rahmawati, Y. (2018). Pemahaman Model Pembelajaran Sebagai Kesiapan Praktik Pengalaman Lapangan (Ppl) Mahasiswa Program Studi Pendidikan Tata Boga. Media Pendidikan, Gizi, Dan Kuliner, 7(1), 76-81.

Sunarsih, E. (2016). Penerapan Model Pembelajaran Project Based Learning (Pjbl) Untuk Meningkatkan Keterampilan Menulis Teks Berita Pada Siswa Kelas Viii Smp Negeri 16 Singkawang. Jp-Bsi (Jurnal Pendidikan Bahasa Dan Sastra Indonesia), 1(2), 65. Https://Doi.Org/10.26737/Jp-Bsi.V1i2.92

Yulianto, Aris, Fatchan .A, Astina, K. (2017). Penerapan Model Pembelajaran Project Based Learning Berbasis Lesson Study Untuk Meningkatkan Keaktifan Belajar Siswa. Jurnal Pendidikan, 2(3), 448453. 